\title{
Tipping the Balance: $C$. albicans Adaptation in Polymicrobial Environments
}

\author{
Amit Ranjan and Anna Dongari-Bagtzoglou * \\ Department of Oral Health and Diagnostic Sciences, School of Dental Medicine, University of Connecticut, \\ Farmington, CT 06030, USA; aranjan@uchc.edu \\ * Correspondence: adongari@uchc.edu
}

Received: 29 August 2018; Accepted: 15 September 2018; Published: 18 September 2018

\begin{abstract}
Candida albicans is a pleiomorphic fungus which co-exists with commensal bacteria in mucosal and skin sites of mammalian hosts. It is also a major co-isolated organism from polymicrobial systemic infections, with high potential for morbidity or mortality in immunocompromised patients. Traditionally, resident mucosal bacteria have been thought to antagonize C. albicans in its ability to colonize or cause infection. However, recent investigations have revealed synergistic relationships with certain bacterial species that colonize the same mucosal sites with $C$. albicans. Such relationships broaden the research landscape in pathogenesis but also contribute to clinical challenges in the prevention or treatment of mucosal candidiasis. This review sheds light on interactions of $C$. albicans and mucosal bacteria, with special emphasis on the effects of the resident bacterial microbiota on C. albicans physiology as they relate to its adaptation in mucosal sites as a commensal colonizer or as a pathogenic organism.
\end{abstract}

Keywords: polymicrobial interactions; Candida albicans; candidiasis; fungal-bacterial interactions

\section{Introduction}

There is ample evidence for cross-kingdom signaling, cross-regulation, antagonism, and synergy between bacteria and C. albicans. As we acquire more information on the composition of microbiota residing in mammalian mucosal tissues using advanced sequencing methodologies, it is imperative to begin to examine how organisms colonizing the same ecological niches modulate the capacity of each other to colonize or infect the host, and how the host regulates homeostasis under these conditions. C. albicans is a fungal organism which can switch from commensal to pathobiont, and is associated with the majority of mucosal infections [1,2]. This review focuses on the effects of the resident bacterial microbiota on C. albicans physiology as they relate to its adaptation in mucosal sites as a commensal colonizer or pathogenic organism.

\section{Mucosal Microbiota Act as an Innate Host Factor That Controls the Switch from Fungal Commensalism to Infection}

\subsection{Effect of Indigenous Bacteria in Mammalian Host Colonization Models}

C. albicans colonizes several mammalian polymicrobial host niches, including oropharyngeal, esophageal, vaginal, and gastrointestinal mucosae, and the skin. In each of these sites it has to compete for space and nutritional resources with other commensal fungi and bacteria and respond to environmental cues that promote a steady state of commensalism or lead to infection. It is widely accepted that in a healthy host, the resident bacteria play an important role in limiting the capacity of Candida for colonization. This may be accomplished by direct fungal-bacterial cell interactions involving secreted bacterial products. For example, certain Enterococcus faecalis strains secrete a 
bacteriocin that promotes a non-filamentous, commensalism-associated phenotype of C. albicans in nematodes and orally inoculated mice [3,4]. In a similar function, a secreted protein of Salmonella enterica attenuates the virulence of $C$. albicans in C. elegans and promotes a symbiotic state in the nematode gut $[5,6]$. Alternatively, resident microbiota may act indirectly to inhibit colonization by enhancing the mucosal immune response to Candida. An example of this is Corynebacterium mastitidis, a member of the resident bacterial microbiota in the murine ocular mucosa, which prevents C. albicans infection by driving IL-17 production from mucosal T cells [7]. Along the same line, Bacteroides thetaiotaomicron, a commensal of the murine intestinal mucosa, prevents $C$. albicans colonization by stimulating the epithelial antimicrobial proteins cathelicidins [8].

Several studies have examined the role of indigenous bacteria in alimentary-tract colonization of healthy mice using combinations of broad-spectrum antibiotics and monitoring the growth of both bacteria and Candida in the post-antibiotic fungal colonization period. Enhanced oropharyngeal and intestinal colonization of $C$. albicans was noted with the most broad-spectrum antibiotics in mice [8-11]. Interestingly, antibiotics, and by extension, indigenous bacteria which are either displaced or overgrown with antibiotic treatment can also affect the outcome of competition between C. albicans and C. glabrata in mouse cecum [12]. It is well-established that commensal anaerobic bacteria are critical in limiting Candida intestinal colonization in mice, and colonization levels are generally proportional to the level of antibiotic depletion of anaerobic bacteria [13]. On the other hand, antibiotics that allow Escherichia coli overgrowth inhibit murine cecum colonization [12]. Along these lines, an increase in Enterococcus species in the stomach [10], caecum [11], and terminal ileum [9], and Streptococcus species in the colon [9] in the post-antibiotic period were associated with increased C. albicans colonization. On the other hand, lactobacilli antagonize C. albicans colonization in lower GI-tract mucosa [9,11], although their role in the oropharyngeal mucosa has not been established in vivo. Using innovative predictive statistical models, Shankar and colleagues [9] showed greater dependence of Candida colonization in the murine ileum and colon on certain bacterial genera than the host cytokine environment in the two sites. These studies revealed that certain bacterial genera (e.g., Veillonella) may influence C. albicans colonization by modulating the GI immune response, whereas others (e.g., Streptococci) may have a direct impact on Candida physiology that does not involve the intestinal immune response [9].

\subsection{Effect of Indigenous Bacteria in Mucosal Candidiasis}

A central tenet in the pathogenesis of mucosal candidiasis is that immunosuppression, or other mucosal barrier-compromising conditions (e.g., local trauma or inflammation) are a prerequisite for infection $[14,15]$. Under inflammatory or immunocompromised host conditions, it is possible that ecological resources, such as space and nutrients, are diverted to favor bacterial species that form mutualistic relationships with $C$. albicans. This, in turn, could lead to a well-coordinated fungal-bacterial dysbiosis which amplifies mucosal damage. Such pathogenic synergy between C. albicans and certain commensal bacterial species was recently revealed in mouse models of infection. For example, in cortisone-immunosuppressed mice, we showed that when C. albicans is orally co-inoculated with mitis-group streptococcal species, there is an increase in oral mucosal biofilms that contributes to Candida virulence [16]. Others have shown pathogenic synergy between C. albicans and Staphylococcus aureus in a similar oral infection model [17]. A peritonitis model from the Noverr laboratory has demonstrated that rates of disease progression and microbial load in mice infected with both $S$. aureus and C. albicans were significantly higher compared to those with monomicrobial infections [18]. In both the oropharyngeal and peritonitis infection models, pathogenic synergy between Gram $(+)$ cocci and C. albicans was shown to be host-response mediated via induction of a significantly higher proinflammatory response $[16,18]$. In the peritonitis model, pathogenic synergy was primarily eicosanoid-mediated [18], whereas in the oropharyngeal model, an exaggerated TLR-2-dependent chemokine and neutrophil response was involved [16]. Similarly, in a zebra fish swim bladder infection model which emulates the human lung mucosa, Pseudomonas aeruginosa promoted C. albicans virulence, associated with higher fungal invasion, proinflammatory cytokine 
production, and immunopathology [19]. These studies were performed with exogenously provided bacteria, and a role for indigenous communities or dysbiosis in fungal pathogenesis has not been examined thus far at any mucosal site. A possible exception to this is the murine gastric mucosa where indigenous enterococci were indirectly suggested to be implicated in the pathogenesis of Candida-induced gastritis [10].

Disease-promoting interactions between Candida and resident mucosal bacteria may be mucosal site-specific. For example, mice pretreated with antibiotics and then inoculated with C. albicans experience significant inflammatory and ulcerative gastric lesions, but do not develop signs of inflammation in the cecum, despite having similar fungal burdens at this site $[10,11]$. Similarly, in the lower GI tract, Gram (-) anaerobes and enteric bacilli limit the growth and dissemination of Candida [20], and after treatment with broad-spectrum antibiotics, C. albicans can invade the gut mucosa [21,22]. In contrast, reports of oropharyngeal candidiasis or oral mucosal invasion after similar antibiotic treatment are rare [23]. Thus, the effect that indigenous bacteria have on mucosal candidiasis is likely to differ at different mucosal sites, due in part to the anatomically distinct innate immune epithelial response to infection, but also due to site-specific differences in the composition of the local microbial communities [24].

A high percentage ( $>60 \%$ ) of $C$. albicans nosocomial and immunocompromised patient infections are polymicrobial, and numerous clinical studies have reported co-isolation of bacteria from human disease samples (reviewed by $\mathrm{O}^{\prime}$ Donnel et al. [25]). For example, P. aeruginosa, S. aureus, and streptococci of the mitis group are frequent co-isolates with $C$. albicans in neonatal bloodstream infections and pulmonary infections in antibiotics-treated immunocompromised patients [26,27]. There is also mounting evidence that $C$. albicans and enterococci co-exist in human disease samples (reviewed by Garsin and Lorenz, [28]). Perhaps the strongest evidence comes from a large-scale retrospective analysis showing that $E$. faecalis was twice as likely to be isolated in Candida-positive sputum or skin samples and even more likely in sepsis [29]. In the oral cavity, E. faecalis and C. albicans were co-isolated in $>10 \%$ of root canal infections [30] and in $>40 \%$ of tongue mucosal lesions in humans [31]. Whether this co-isolation reflects similar mucosal adaptation strategies or local dysbiotic shifts which contribute to pathogenic synergy remains unclear. Most human clinical studies which have identified both C. albicans and bacteria in disease samples are cross-sectional and observational, and cannot causally link these organisms to disease progression or prevention. No study to date has directly or systematically assessed the role of indigenous bacteria in the pathogenesis of mucosal candidiasis in humans.

\section{Bacterial Signals Trigger Distinct Phenotypic Responses in C. albicans Associated with Commensalism or Virulence}

\subsection{Effect of Bacterial Interactions on Filamentation}

Because $C$. albicans has to adapt in polymicrobial mucosal environments, it is not surprising that it responds to bacterial signals with distinct phenotypic changes. The most readily identifiable phenotypic response to these signals is their effect on hyphal morphogenesis. In vivo indirect evidence supporting the fact that $C$. albicans responds to indigenous microbiota by activating filamentation pathways comes from works with germ-free mice. In these mice, C. albicans exists in the lower GI tract preferentially in the yeast form, whereas a mix of hyphae and yeast cells colonize the same sites in conventional mice [32]. In contrast, C. albicans forms highly invasive hyphae on the tongues of germ-free piglets independently of the Efg1 filamentation pathway, since deletion of efg1 did not abrogate filamentation at this site [33]. To complicate matters further, recent work from our laboratory showed activation of the Efg1 filamentation pathway in C. albicans by mitis-group streptococci, not indigenous in the mouse oral cavity, leading to more invasive oral infection in a murine oropharyngeal candidiasis model $[34,35]$. These observations raise the possibility that resident bacteria modulate the ability of fungal cells to form tissue-invasive hyphae in a mucosal site- and local microbiota-specific manner. 
Interactions between $C$. albicans and bacteria that affect filamentation may be contact-dependent or mediated by secreted bacterial signals. Most published studies have focused on bacterial secreted products that inhibit the hyphal switch because of their translational potential in preventive or therapeutic applications. Secreted signals include N-acyl homoserine lactones, the primary quorum sensing molecules in Gram (-) bacteria produced when the cell density is high. One of these molecules produced by P. aeruginosa inhibit the yeast-to-hyphae switch [36], but hypoxic conditions dampen its production and limit its effect on filamentation [37], highlighting the fact that environmental conditions, such as site-specific oxygen tension, may modify the outcome of these interactions. Autoinducer-2, another secreted bacterial quorum-sensing molecule, has been reported to be involved in both enhancing [38] and suppressing filamentation [39], depending on the bacterial species-however, the exact mechanisms are not completely understood. Pyocyanin, produced by P. aeruginosa in the early stationary phase, inhibits the switch by reducing intracellular cAMP, high levels of which signal the transition from yeast to hyphae [40]. Streptococcal competence-stimulating peptides may also disrupt hyphal morphogenesis, although this effect appears to be streptococcal species-dependent [41,42]. Finally, a secreted bacteriocin by E. faecalis, which is partially dependent on the Fsr quorum-sensing pathway, inhibits the switch to hyphae [3].

Bacterial cell wall components, such as peptidoglycan fragments and LPS, have been shown to exert opposing effects, with the former inducing [43] and the latter decreasing [44] filamentation. Hydrogen peroxide, a major metabolic byproduct released by actively growing streptococci, although genotoxic in high concentrations, can stimulate filamentous growth in C. albicans at lower concentrations [45,46]. Early work by Noverr and Huffnagle [47] demonstrated that several live Lactobacillus species inhibit C. albicans hyphal transformation via soluble metabolic products and possibly short-chain fatty acids, such as butyric acid. By significantly reducing the environmental $\mathrm{pH}$, lactic acids produced by lactic-acid bacteria (e.g., streptococci, enterococci, lactobacilli) have the ability to negatively influence filamentation, although under glucose-limiting conditions, C. albicans can neutralize their effect by excreting ammonia [48]. Contact-dependent signals with a detrimental effect on hyphae have also been identified in certain Gram (-) bacteria (e.g., Acinetobacter baumannii) [49].

\subsection{Effect of Bacterial Interactions on C. albicans Metabolism, Growth, and Biofilm Formation}

Metabolic interactions within polymicrobial communities in mucosal sites play a major role in the adaptation of each community member to these sites. In support of a possible role of indigenous intestinal bacteria in fungal metabolism, a recent study by Noble et al. has shown that the passage of $C$. albicans through the murine gastrointestinal (GI) tract induces a fungal-cell phenotype termed "GUT", which differs both morphologically (elongated yeast cells) and metabolically from cells growing in other conditions [50]. In particular, these fungal cells express transcriptome-enriched genes involved in the catabolism of bacterial products, such as fatty acids and $N$-acetylglucosamine. Work from the Kumamoto lab also showed that hypercolonization in the cecum by certain mutant C. albicans strains was associated with an increased ability to utilize non-fermentable carbon sources such as short chain fatty acids, produced by Bacteroides in the lower GI tract [51]. Therefore, it is tempting to speculate that intestinal bacteria contribute to the metabolic adaptation and growth of C. albicans in the intestinal mucosa, although direct comparisons in gnotobiotic mice were not performed in these studies.

More direct evidence for the role of bacteria in influencing C. albicans metabolism comes from in vitro studies. L. ramnosus growing with C. albicans on epithelial monolayers in vitro revealed metabolic reprogramming in C. albicans, primarily by induction of fatty acid metabolism, glyoxylate pathway-, and gluconeogenesis pathway-related genes, while the glucose metabolic pathway was downregulated. This may promote growth in mucosal sites rich in commensal lactobacilli, such as the intestinal and oral mucosa, under conditions of nutritional compromise or lower glucose availability [52]. A recent transcriptomic analysis of the C. albicans response to S. gordonii, another oral commensal, revealed that biosynthetic genes involved in arginine production were enriched in mixed 
biofilms, whereas transcription of the arginase gene (car1) was downregulated [53]. This may represent a fungal cell response to high amounts of $\mathrm{H}_{2} \mathrm{O}_{2}$ produced by this streptococcal species $[54,55]$.

In mixed biofilms with P. aeruginosa in vitro, C. albicans exhibits lower metabolic activity with a decrease in iron-dependent processes due to increased iron sequestration by bacteria. In these studies, increased secretion of a bacterial-specific siderophore has been suggested to decrease availability of iron to fungal cells and reduce their metabolic activity [56]. Glycolysis is also decreased in C. albicans biofilms treated with high amounts of P. aeruginosa LPS [44].

Since hyphal growth is a main feature in mature biofilms, in theory, any bacterial signal that promotes or inhibits filamentation can alter the ability of $C$. albicans to grow in the biofilm form. Thus, it is not surprising that acyl-homoserine lactones from $P$. aeruginosa have anti-biofilm activity and cause dispersal of yeast cells from biofilms [57]. In contrast to P. aeruginosa, several oral streptococcal species have been reported to enhance $C$. albicans biofilms by promoting hyphal growth. In particular, mitis-group streptococci, such as S. oralis and S. gordonii, form co-aggregation interactions with hypha-associated cell wall adhesins, such as Als1 and Als3, which increase biofilm biomass [16,58,59]. On the other hand, oral viridans streptococci, principally represented by $S$. mutans, promote fungal biofilm formation on tooth surfaces that are normally not colonized by $C$. albicans by depositing bacterial extracellular polysaccharides ( $\alpha$-glucans) on the surface of fungal cells, which promote co-aggregation interactions [60].

\section{Bacteria Influence $C$. albicans Gene Expression and Site-Specific Adaptation in Mammalian Host Niches}

C. albicans responds rapidly to environmental conditions in different mucosal sites. Mucosal-sitespecific differences in fungal gene expression are expected due to the requirement for adaptation in environments with different mucosal physiology, but also with different indigenous bacterial microbiota. For example, upregulation of oxidative stress genes (e.g., trx1, cat1) may be more important in upper alimentary-tract mucosal adaptation since the dominant streptococcal and lactobacilli taxa in this site can generate cytotoxic levels of $\mathrm{H}_{2} \mathrm{O}_{2}$ [55]. Gene expression changes during adaptation can be monitored locally at the transcriptional level by in vivo gene expression profiling to identify functional adjustments of the fungus within polymicrobial communities. Two studies have examined the $C$. albicans transcriptome in situ, in mucosal niches that harbor diverse indigenous bacterial communities (i.e., intestinal and vaginal mucosa) [51,61]. However, neither study compared fungal transcriptomic profiles at the same sites in conventional versus gnotobiotic mice, therefore a direct or indirect influence of indigenous commensals on $C$. albicans gene expression during adaptation in these sites was not examined.

Although the role of bacteria was not directly addressed, a microarray analysis of C. albicans gene expression during post-antibiotic murine intestinal colonization has provided some insights by comparing the transcriptional responses during adaptation in the ileum and cecum of the same mice [51]. The two sites differ by the considerably higher presence of bacteria and their short-chain fatty acids in cecum compared to ileum. Only approximately half of the differentially regulated genes in the two sites overlapped, and these included genes involved in host interactions, pathogenesis, and metabolism. Interspecies-interaction genes were not identified in the overlapping gene ontology categories, reflecting differences in bacterial environments. In the murine vaginitis model, RNAseq analysis of the most highly expressed genes of $C$. albicans revealed certain genes associated with interspecies interactions (e.g., sod5, involved in oxidative responses)-however, the role of vaginal commensal bacteria, such as lactobacilli, which can induce oxidative stress in C. albicans by releasing $\mathrm{H}_{2} \mathrm{O}_{2}$ was not examined [61].

Most studies on the effects of bacteria on C. albicans gene expression have used in vitro models. For example, the influence of mixed biofilm growth with enteric bacteria on C. albicans global gene expression was studied in biofilms growing on polystyrene surfaces using microarray analysis. Strongly upregulated by coculture with Klebsiella pneumoniae, E. coli and E. faecalis were the "master" regulator 
of white-opaque-switching WOR1, which, however, did not allow a complete switch from the white to opaque phenotype [62]. Two other studies independently confirmed that this regulator was also upregulated by the intestinal mucosal environment in vivo [50,51]. This raises the possibility that upregulation of WOR1 and at least partial induction of this phenotypic switch is an adaptive response of $C$. albicans to the exposure to enteric commensals in the intestinal milieu.

Several studies have shown upregulation of virulence-associated genes by certain bacterial species. Gene-expression analysis of C. albicans forming polymicrobial biofilms with oral bacteria on epithelial constructs in vitro showed that known virulence genes encoding certain secreted aspartyl-proteinases (sap4, sap6) which facilitate fungal invasion [63] were up-regulated [64]. In fact, using an oropharyngeal candidiasis model, we showed that co-inoculation of mice with $S$. oralis caused increased expression of sap4, sap5, and sap6 genes and also increased systemic dissemination, implicating commensal bacteria in enhanced virulence [34]. More recently, RNAseq analyses of C. albicans forming biofilms with S. gordonii in vitro showed filamentation- and adhesion-related genes involved in pathogenesis and virulence being upregulated (e.g., als1, tec1) [53]. Other genes included hyr1, which may protect $C$. albicans from neutrophil damage during adaptation in mucosal sites [65].

\section{C. albicans Has Reciprocal Effects on the Mucosal Bacterial Microbiota}

The influence of $C$. albicans on the resident bacterial composition at mucosal sites has seldom been addressed in the literature, and most studies investigating this aspect of fungal pathogenesis were conducted in the murine intestinal mucosa. Low-level colonization of the murine cecum of healthy C57B/L6J mice by C. albicans led to shifts in the community structure, such that bacterial communities in the colonized mice were distinct from and more diverse than naive mice [10]. It has been suggested that $C$. albicans non-pathogenic colonization of the lower GI tract in mice may promote the growth of Bacteroidetes [11]. Recent evidence has shown that introduction of $C$. albicans in the gastric or intestinal mucosa of antibiotics-treated mice displaces lactobacilli and drives a preferential re-colonization by enterococci $[10,11]$. In a nematode gut infection model, C. albicans-produced farnesol inhibited A. baumannii growth [49].

Although ethanol produced by C. albicans stimulated in vitro biofilm formation in P. aeruginosa [66], results from murine infection models dispute the notion that $C$. albicans aggravates $P$. aeruginosa virulence. For example, $C$. albicans short-term pulmonary colonization prior to P. aeruginosa inoculation caused a reduction in the $P$. aeruginosa bacterial load by recruiting natural killer cells and increasing IL-22 in lung tissues $[67,68]$. Similarly, in a murine intestinal infection model, C. albicans secreted factors inhibited the expression of siderophores as well as cytotoxic molecules produced by P. aeruginosa, thereby reducing its virulence [69].

In oral infection models, the introduction of $C$. albicans to the oral cavity of mice facilitates colonization of mucosal surfaces by $S$. oralis, a streptococcal species that preferentially colonizes tooth surfaces [16]. Hence, just as S. mutans creates favorable conditions for tooth colonization by C. albicans [70], C. albicans creates favorable conditions for mucosal colonization for other streptococcal species that normally colonize teeth [71]. This reciprocal relationship extends to streptococcal infection models with $S$. mutans, where $C$. albicans enhances the cariogenicity of streptococci by promoting expression of the biofilm matrix synthesizing enzyme, GtfB [72].

In vitro biofilm experiments have shown that $C$. albicans biofilms create hypoxic or anoxic microniches that allow for the growth of obligate anaerobic bacteria under ambient oxygen tension [62,73]. C. albicans inoculated in microcosm biofilms growing directly from saliva can induce growth of anaerobic bacteria under aerobic conditions via mitochondrial oxygen consumption, which causes a micro-aerobic/anaerobic niche [73]. A similar growth advantage was conferred to anaerobic enteric bacteria (Clostridium perfringens and Bacillus fragilis) by C. albicans growing on polystyrene plates [62]. A similar effect was also shown in mixed biofilms with facultative streptococcal species that thrive in lower oxygen tensions [74]. 


\section{Unanswered Questions on Fungal-Bacterial Interactions in Human Health and Disease}

In recent years, there has been a growing appreciation of the fact that $C$. albicans almost never exists in isolation from other microorganisms in mucosal sites. Thus, the pathogenesis of candidiasis has to be studied both in the context of site-specific immunity and site-specific microbiota. Mouse studies of C. albicans have largely focused on its virulence, rather than on its ability to co-exist as a commensal or pathogen in the alimentary tract microbiota. As such, little is known about the microbiome-mediated interactions that control the switch from commensalism to infection. Although several studies have shown pathogenic synergy between C. albicans and experimentally inoculated bacteria, very few studies have focused on the interplay between $C$. albicans and indigenous mucosal bacteria in health and disease.

The examination of fungal adaptation within different polymicrobial mucosal environments in the same hosts using transcriptomic methods has not received significant research attention. Although studies over the past two decades have performed detailed transcriptomic analyses in deep organs which are sterile, a gap in knowledge still exists on the role of specific bacteria in fungal adaptation within different polymicrobial mucosal habitats [75,76]. In addition, the use of antibiotics as part of the fungal infection protocol in oral models to improve fungal burdens has obscured the role of resident bacteria in fungal infection [17]. Although CFU counts increase with antibiotics in the oral mucosa [77], no study has shown that this is accompanied by inflammatory changes unless an immunosuppressive regimen is also administered.

The clinical significance of bacterial pathobionts in fungal pathogenesis is the recalcitrance of most Candida infections to antifungals, since current therapies do not address the potential influence of these indigenous bacteria in virulence. Targeting the organism that is crucial for pathogenicity in mixed biofilm infections with antimicrobials is a challenge, although broad-spectrum antimicrobials such as ethanol or chlorhexidine, in theory, may be effective. However, if a bacterial partner is a key factor in increasing C. albicans biofilms in host niches that do not otherwise provide fungal adhesion sites, control of infection at these sites may be accomplished solely with an effective antibiotic regimen without the need for an antifungal. Translational studies that can pursue such novel preventive or therapeutic strategies in mucosal C. albicans infections are needed.

Several studies have examined the global transcriptome of $C$. albicans colonizing the lower murine GI tract after antibiotics treatment, and some transcriptome studies were performed in kidneys/livers in the intravenous fungal inoculation model $[75,76,78-80]$. However, there are no studies addressing the functional gene adaptation of $C$. albicans in the alimentary tract of mice harboring unperturbed bacterial communities, and no studies are available addressing the oropharyngeal colonization site. One reason for this, and one of the biggest challenges for global fungal transcription analysis in mucosal and other tissues, is the inadequate amounts of fungal RNA recovered amidst a high abundance of mammalian transcripts in these samples. This is especially problematic with eukaryotic pathogens since they share the polyadenylation of mRNA with their hosts, meaning poly-A enrichment protocols cannot enrich fungal transcripts. High-quality gene-expression analysis can be accomplished with 2 million reads per sample for fungi $[79,81]$. However, this level of coverage is not accomplished even in infected (i.e., not merely colonized) mucosal tissues, as Bruno and colleagues have shown in a murine vaginitis model [61]. More studies with novel fungal gene enrichment strategies are needed to compare the fungal transcriptomic responses in the same mucosal sites in gnotobiotic and conventional mice.

Polymicrobial infections with C. albicans and bacteria are not only more prevalent, but also more lethal in immunosuppressed patients $[82,83]$. We propose a pathogenesis model whereby immunosuppression coupled with $C$. albicans colonization results in a bacterial dysbiosis with dominant species that have the ability to promote fungal virulence, thus acting as synergistic pathobionts (Figure 1). However, studies exploring shifts in the mucosal microbiome during pharmacologic immunosuppression and fungal infection in humans are not available and are sorely needed. Immunosuppression can have a detrimental role in shaping the local microbial environment where 
C. albicans infections occur. For example, a study of the colon microbiome in transplant patients receiving immunosuppressants showed major shifts with a predominant increase in the proportion of enterococci and a decrease in other Firmicutes, starting in the immediate post-transplant period when these patients are also more susceptible to gastrointestinal candidiasis [84]. Interestingly, in cases of graft-versus-host disease, this shift was even more pronounced, raising the possibility of enterococci acting as pathobionts in this clinical setting [84].

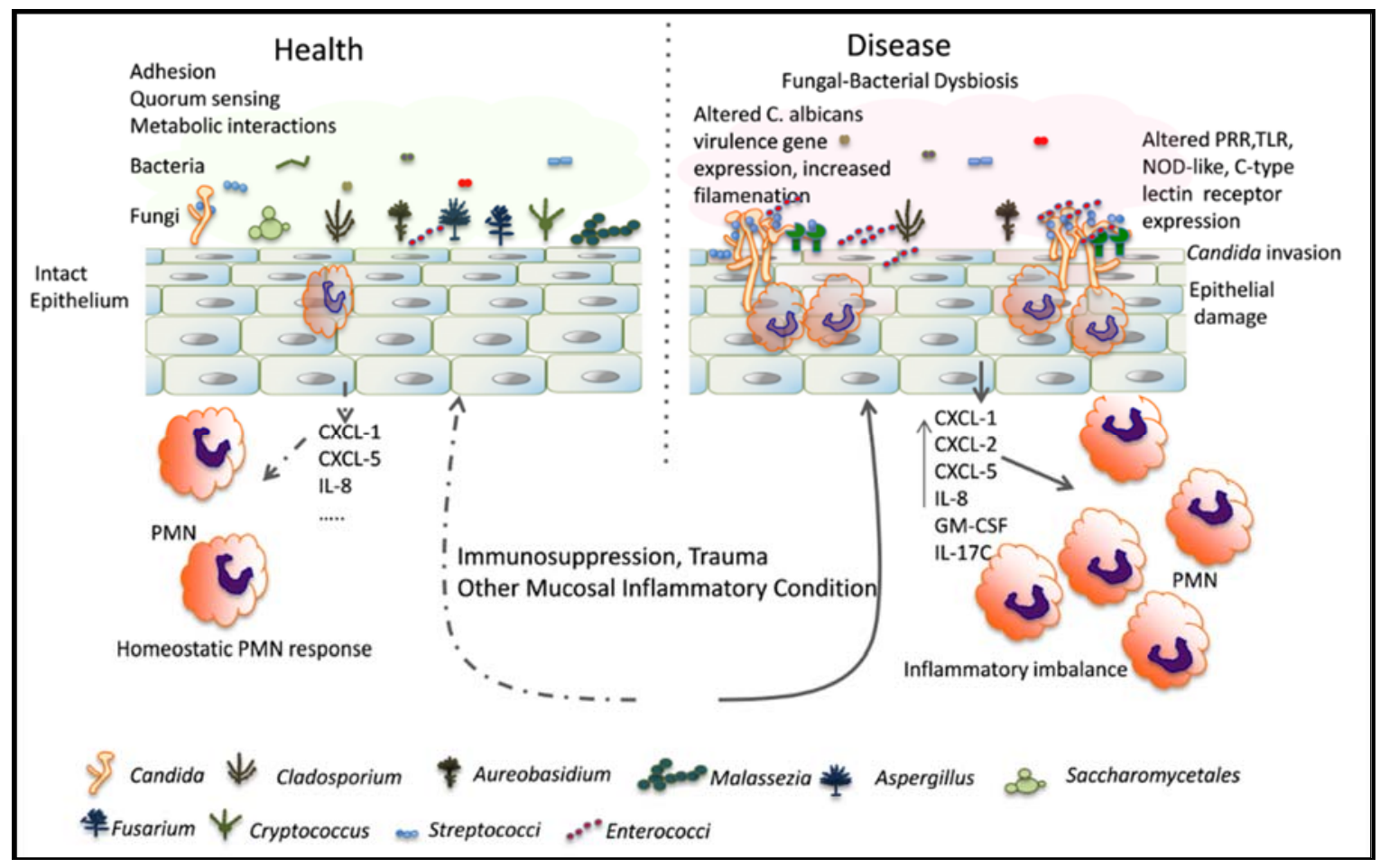

Figure 1. Relationship between C. albicans and resident mucosal bacteria in heath and disease: Immunosuppression is associated with a dysbiotic state characterized by overgrowth of Candida and certain resident bacterial species. Bacteria may interact with Candida species to augment the mucosal inflammatory response, resulting in epithelial damage. Alternatively, bacteria can directly influence filamentation and virulence gene expression to increase mucosal invasion. PRR: pattern recognition receptors; TLR: toll-like receptors; NOD: nucleotide-oligomerization domain.

In conclusion, the pathogenesis of mucosal candidiasis is integrally related to the physiology of the resident microbial communities within which $C$. albicans adapts to either colonize or cause disease. Resident bacteria can directly modulate the virulence of $C$. albicans by altering virulence gene expression, or indirectly by modulating the host response. Therefore, "niche-specific" fungal responses to the local microbiota and reciprocal effects on mucosal bacteria are an important component of fungal pathogenesis in non-sterile sites. In future studies, mucosal infection models should take advantage of the knowledge gained from the metagenomics field to identify resident commensals with the potential to become pathobionts and define mechanisms of pathogenic synergy with Candida. These studies will pave the way for better preventative and therapeutic strategies in mucosal candidiasis.

Author Contributions: A.R.: literature search, manuscript formatting, A.D.-B.: manuscript writing.

Funding: NIH/NIDCR RO1DE013986.

Conflicts of Interest: The authors declare no conflict of interest. 


\section{References}

1. Richardson, J.P.; Moyes, D.L.; Ho, J.; Naglik, J.R. Candida innate immunity at the mucosa. Semin. Cell Dev. Biol. 2018. [CrossRef] [PubMed]

2. Neville, B.A.; d'Enfert, C.; Bougnoux, M.E. Candida albicans commensalism in the gastrointestinal tract. FEMS Yeast Res. 2015, 15. [CrossRef] [PubMed]

3. Cruz, M.R.; Graham, C.E.; Gagliano, B.C.; Lorenz, M.C.; Garsin, D.A. Enterococcus faecalis inhibits hyphal morphogenesis and virulence of Candida albicans. Infect. Immun. 2013, 81, 189-200. [CrossRef] [PubMed]

4. Graham, C.E.; Cruz, M.R.; Garsin, D.A.; Lorenz, M.C. Enterococcus faecalis bacteriocin entv inhibits hyphal morphogenesis, biofilm formation, and virulence of Candida albicans. Proc. Natl. Acad. Sci. USA 2017, 114, 4507-4512. [CrossRef] [PubMed]

5. Tampakakis, E.; Peleg, A.Y.; Mylonakis, E. Interaction of Candida albicans with an intestinal pathogen, salmonella enterica serovar typhimurium. Eukaryot. Cell 2009, 8, 732-737. [CrossRef] [PubMed]

6. Kim, Y.; Mylonakis, E. Killing of Candida albicans filaments by salmonella enterica serovar typhimurium is mediated by sopb effectors, parts of a type iii secretion system. Eukaryot. Cell 2011, 10, 782-790. [CrossRef] [PubMed]

7. Dutzan, N.; Abusleme, L.; Bridgeman, H.; Greenwell-Wild, T.; Zangerle-Murray, T.; Fife, M.E.; Bouladoux, N.; Linley, H.; Brenchley, L.; Wemyss, K.; et al. On-going mechanical damage from mastication drives homeostatic th17 cell responses at the oral barrier. Immunity 2017, 46, 133-147. [CrossRef] [PubMed]

8. Fan, D.; Coughlin, L.A.; Neubauer, M.M.; Kim, J.; Kim, M.S.; Zhan, X.; Simms-Waldrip, T.R.; Xie, Y.; Hooper, L.V.; Koh, A.Y. Activation of hif-1alpha and 1l-37 by commensal bacteria inhibits Candida albicans colonization. Nat. Med. 2015, 21, 808-814. [CrossRef] [PubMed]

9. Shankar, J.; Solis, N.V.; Mounaud, S.; Szpakowski, S.; Liu, H.; Losada, L.; Nierman, W.C.; Filler, S.G. Using bayesian modelling to investigate factors governing antibiotic-induced Candida albicans colonization of the gi tract. Sci. Rep. 2015, 5, 8131. [CrossRef] [PubMed]

10. Mason, K.L.; Erb Downward, J.R.; Falkowski, N.R.; Young, V.B.; Kao, J.Y.; Huffnagle, G.B. Interplay between the gastric bacterial microbiota and Candida albicans during postantibiotic recolonization and gastritis. Infect. Immun. 2012, 80, 150-158. [CrossRef] [PubMed]

11. Mason, K.L.; Erb Downward, J.R.; Mason, K.D.; Falkowski, N.R.; Eaton, K.A.; Kao, J.Y.; Young, V.B.; Huffnagle, G.B. Candida albicans and bacterial microbiota interactions in the cecum during recolonization following broad-spectrum antibiotic therapy. Infect. Immun. 2012, 80, 3371-3380. [CrossRef] [PubMed]

12. Henry-Stanley, M.J.; Garni, R.M.; Alice Johnson, M.; Bendel, C.M.; Wells, C.L. Comparative abilities of Candida glabrata and Candida albicans to colonize and translocate from the intestinal tract of antibiotic-treated mice. Microb. Ecol. Health Dis. 2005, 17, 129-137. [CrossRef]

13. Koh, A.Y. Murine models of Candida gastrointestinal colonization and dissemination. Eukaryot. Cell 2013, 12, 1416-1422. [CrossRef] [PubMed]

14. Koh, A.Y.; Kohler, J.R.; Coggshall, K.T.; Van Rooijen, N.; Pier, G.B. Mucosal damage and neutropenia are required for Candida albicans dissemination. PLoS Pathog. 2008, 4, e35. [CrossRef] [PubMed]

15. Dongari-Bagtzoglou, A.; Fidel, P.L., Jr. The host cytokine responses and protective immunity in oropharyngeal candidiasis. J. Dent. Res. 2005, 84, 966-977. [CrossRef] [PubMed]

16. Xu, H.; Sobue, T.; Thompson, A.; Xie, Z.; Poon, K.; Ricker, A.; Cervantes, J.; Diaz, P.I.; Dongari-Bagtzoglou, A. Streptococcal co-infection augments Candida pathogenicity by amplifying the mucosal inflammatory response. Cell. Microbiol. 2014, 16, 214-231. [CrossRef] [PubMed]

17. Kong, E.F.; Kucharikova, S.; Van Dijck, P.; Peters, B.M.; Shirtliff, M.E.; Jabra-Rizk, M.A. Clinical implications of oral candidiasis: Host tissue damage and disseminated bacterial disease. Infect. Immun. 2015, 83, 604-613. [CrossRef] [PubMed]

18. Peters, B.M.; Noverr, M.C. Candida albicans-Staphylococcus aureus polymicrobial peritonitis modulates host innate immunity. Infect. Immun. 2013, 81, 2178-2189. [CrossRef] [PubMed]

19. Bergeron, A.C.; Seman, B.G.; Hammond, J.H.; Archambault, L.S.; Hogan, D.A.; Wheeler, R.T. Candida and pseudomonas interact to enhance virulence of mucosal infection in transparent zebrafish. Infect. Immun. 2017. [CrossRef] [PubMed]

20. Sjovall, J.; Huitfeldt, B.; Magni, L.; Nord, C.E. Effect of beta-lactam prodrugs on human intestinal microflora. Scand. J. Infect. Dis. Suppl. 1986, 49, 73-84. [PubMed] 
21. Ponnuvel, K.M.; Rajkumar, R.; Menon, T.; Sankaranarayanan, V.S. Role of Candida in indirect pathogenesis of antibiotic associated diarrhoea in infants. Mycopathologia 1996, 135, 145-147. [CrossRef] [PubMed]

22. Krause, R.; Schwab, E.; Bachhiesl, D.; Daxbock, F.; Wenisch, C.; Krejs, G.J.; Reisinger, E.C. Role of Candida in antibiotic-associated diarrhea. J. Infect. Dis. 2001, 184, 1065-1069. [CrossRef] [PubMed]

23. Gligorov, J.; Bastit, L.; Gervais, H.; Henni, M.; Kahila, W.; Lepille, D.; Luporsi, E.; Sasso, G.; Varette, C.; Azria, D.; et al. Prevalence and treatment management of oropharyngeal candidiasis in cancer patients: Results of the french candidoscope study. Int. J. Radiat. Oncol. Biol. Phys. 2011, 80, 532-539. [CrossRef] [PubMed]

24. Yano, J.; Lilly, E.; Barousse, M.; Fidel, P.L., Jr. Epithelial cell-derived s100 calcium-binding proteins as key mediators in the hallmark acute neutrophil response during Candida vaginitis. Infect. Immun. 2010, 78, 5126-5137. [CrossRef] [PubMed]

25. O'Donnell, L.E.; Millhouse, E.; Sherry, L.; Kean, R.; Malcolm, J.; Nile, C.J.; Ramage, G. Polymicrobial Candida biofilms: Friends and foe in the oral cavity. FEMS Yeast Res. 2015, 15. [CrossRef]

26. Pammi, M.; Zhong, D.; Johnson, Y.; Revell, P.; Versalovic, J. Polymicrobial bloodstream infections in the neonatal intensive care unit are associated with increased mortality: A case-control study. BMC Infect. Dis. 2014, 14, 390. [CrossRef] [PubMed]

27. Maeda, Y.; Elborn, J.S.; Parkins, M.D.; Reihill, J.; Goldsmith, C.E.; Coulter, W.A.; Mason, C.; Millar, B.C.; Dooley, J.S.; Lowery, C.J.; et al. Population structure and characterization of viridans group streptococci (vgs) including streptococcus pneumoniae isolated from adult patients with cystic fibrosis (cf). J. Cyst. Fibros. 2011, 10, 133-139. [CrossRef] [PubMed]

28. Garsin, D.A.; Lorenz, M.C. Candida albicans and Enterococcus faecalis in the gut: Synergy in commensalism? Gut Microbes 2013, 4, 409-415. [CrossRef] [PubMed]

29. Hermann, C.; Hermann, J.; Munzel, U.; Ruchel, R. Bacterial flora accompanying Candida yeasts in clinical specimens. Mycoses 1999, 42, 619-627. [CrossRef] [PubMed]

30. Kovac, J.; Kovac, D.; Slobodnikova, L.; Kotulova, D. Enterococcus faecalis and Candida albicans in the dental root canal and periapical infections. Bratisl. Lek. Listy 2013, 114, 716-720. [PubMed]

31. Dahlen, G.; Blomqvist, S.; Almstahl, A.; Carlen, A. Virulence factors and antibiotic susceptibility in enterococci isolated from oral mucosal and deep infections. J. Oral Microbiol. 2012, 4. [CrossRef] [PubMed]

32. Bohm, L.; Torsin, S.; Tint, S.H.; Eckstein, M.T.; Ludwig, T.; Perez, J.C. The yeast form of the fungus Candida albicans promotes persistence in the gut of gnotobiotic mice. PLoS Pathog. 2017, 13, e1006699. [CrossRef] [PubMed]

33. Riggle, P.J.; Andrutis, K.A.; Chen, X.; Tzipori, S.R.; Kumamoto, C.A. Invasive lesions containing filamentous forms produced by a Candida albicans mutant that is defective in filamentous growth in culture. Infect. Immun. 1999, 67, 3649-3652. [PubMed]

34. Xu, H.; Sobue, T.; Bertolini, M.; Thompson, A.; Vickerman, M.; Nobile, C.J.; Dongari-Bagtzoglou, A.S. Oralis activates the efg1 filamentation pathway in C. albicans to promote cross-kingdom interactions and mucosal biofilms. Virulence 2017, 8, 1602-1617. [CrossRef] [PubMed]

35. Bertolini, M.M.; Xu, H.; Sobue, T.; Nobile, C.J.; Del Bel Cury, A.A.; Dongari-Bagtzoglou, A. Candida-streptococcal mucosal biofilms display distinct structural and virulence characteristics depending on growth conditions and hyphal morphotypes. Mol. Oral Microbiol. 2015, 30, 307-322. [CrossRef] [PubMed]

36. McAlester, G.; O'Gara, F.; Morrissey, J.P. Signal-mediated interactions between Pseudomonas aeruginosa and Candida albicans. J. Med. Microbiol. 2008, 57, 563-569. [CrossRef] [PubMed]

37. Trejo-Hernandez, A.; Andrade-Dominguez, A.; Hernandez, M.; Encarnacion, S. Interspecies competition triggers virulence and mutability in Candida albicans-Pseudomonas aeruginosa mixed biofilms. ISME J. 2014, 8, 1974-1988. [CrossRef] [PubMed]

38. Bamford, C.V.; d'Mello, A.; Nobbs, A.H.; Dutton, L.C.; Vickerman, M.M.; Jenkinson, H.F. Streptococcus gordonii modulates Candida albicans biofilm formation through intergeneric communication. Infect. Immun. 2009, 77, 3696-3704. [CrossRef] [PubMed]

39. Bachtiar, E.W.; Bachtiar, B.M.; Jarosz, L.M.; Amir, L.R.; Sunarto, H.; Ganin, H.; Meijler, M.M.; Krom, B.P. Ai-2 of aggregatibacter actinomycetemcomitans inhibits Candida albicans biofilm formation. Front. Cell. Infect. Microbiol. 2014, 4, 94. [CrossRef] [PubMed]

40. Kerr, J.R.; Taylor, G.W.; Rutman, A.; Hoiby, N.; Cole, P.J.; Wilson, R. Pseudomonas aeruginosa pyocyanin and 1-hydroxyphenazine inhibit fungal growth. J. Clin. Pathol. 1999, 52, 385-387. [CrossRef] [PubMed] 
41. Jack, A.A.; Daniels, D.E.; Jepson, M.A.; Vickerman, M.M.; Lamont, R.J.; Jenkinson, H.F.; Nobbs, A.H. Streptococcus gordonii comcde (competence) operon modulates biofilm formation with Candida albicans. Microbiology 2015, 161, 411-421. [CrossRef] [PubMed]

42. Jarosz, L.M.; Deng, D.M.; van der Mei, H.C.; Crielaard, W.; Krom, B.P. Streptococcus mutans competence-stimulating peptide inhibits Candida albicans hypha formation. Eukaryot. Cell 2009, 8, 1658-1664. [CrossRef] [PubMed]

43. Xu, X.L.; Lee, R.T.; Fang, H.M.; Wang, Y.M.; Li, R.; Zou, H.; Zhu, Y.; Wang, Y. Bacterial peptidoglycan triggers Candida albicans hyphal growth by directly activating the adenylyl cyclase cyr1p. Cell Host Microbe 2008, 4, 28-39. [CrossRef] [PubMed]

44. Bandara, H.M.; BP, K.C.; Watt, R.M.; Jin, L.J.; Samaranayake, L.P. Pseudomonas aeruginosa lipopolysaccharide inhibits Candida albicans hyphae formation and alters gene expression during biofilm development. Mol. Oral Microbiol. 2013, 28, 54-69. [CrossRef] [PubMed]

45. Barnard, J.P.; Stinson, M.W. The alpha-hemolysin of Streptococcus gordonii is hydrogen peroxide. Infect. Immun. 1996, 64, 3853-3857. [PubMed]

46. Nasution, O.; Srinivasa, K.; Kim, M.; Kim, Y.J.; Kim, W.; Jeong, W.; Choi, W. Hydrogen peroxide induces hyphal differentiation in Candida albicans. Eukaryot. Cell 2008, 7, 2008-2011. [CrossRef] [PubMed]

47. Noverr, M.C.; Huffnagle, G.B. Regulation of Candida albicans morphogenesis by fatty acid metabolites. Infect. Immun. 2004, 72, 6206-6210. [CrossRef] [PubMed]

48. Vylkova, S.; Carman, A.J.; Danhof, H.A.; Collette, J.R.; Zhou, H.; Lorenz, M.C. The fungal pathogen Candida albicans autoinduces hyphal morphogenesis by raising extracellular pH. MBio 2011, 2, e00055-00011. [CrossRef] [PubMed]

49. Peleg, A.Y.; Tampakakis, E.; Fuchs, B.B.; Eliopoulos, G.M.; Moellering, R.C., Jr.; Mylonakis, E. Prokaryote-eukaryote interactions identified by using caenorhabditis elegans. Proc. Natl. Acad. Sci. USA 2008, 105, 14585-14590. [CrossRef] [PubMed]

50. Pande, K.; Chen, C.; Noble, S.M. Passage through the mammalian gut triggers a phenotypic switch that promotes Candida albicans commensalism. Nat. Genet. 2013, 45, 1088-1091. [CrossRef] [PubMed]

51. Pierce, J.V.; Dignard, D.; Whiteway, M.; Kumamoto, C.A. Normal adaptation of Candida albicans to the murine gastrointestinal tract requires efg1p-dependent regulation of metabolic and host defense genes. Eukaryot. Cell 2013, 12, 37-49. [CrossRef] [PubMed]

52. Mailander-Sanchez, D.; Braunsdorf, C.; Grumaz, C.; Muller, C.; Lorenz, S.; Stevens, P.; Wagener, J.; Hebecker, B.; Hube, B.; Bracher, F.; et al. Antifungal defense of probiotic lactobacillus rhamnosus gg is mediated by blocking adhesion and nutrient depletion. PLOS ONE 2017, 12, e0184438. [CrossRef] [PubMed]

53. Dutton, L.C.; Paszkiewicz, K.H.; Silverman, R.J.; Splatt, P.R.; Shaw, S.; Nobbs, A.H.; Lamont, R.J.; Jenkinson, H.F.; Ramsdale, M. Transcriptional landscape of trans-kingdom communication between Candida albicans and Streptococcus gordonii. Mol. Oral Microbiol. 2016, 31, 136-161. [CrossRef] [PubMed]

54. Jimenez-Lopez, C.; Collette, J.R.; Brothers, K.M.; Shepardson, K.M.; Cramer, R.A.; Wheeler, R.T.; Lorenz, M.C. Candida albicans induces arginine biosynthetic genes in response to host-derived reactive oxygen species. Eukaryot. Cell 2013, 12, 91-100. [CrossRef] [PubMed]

55. Jenkinson, H.F.; Lala, H.C.; Shepherd, M.G. Coaggregation of streptococcus sanguis and other streptococci with Candida albicans. Infect. Immun. 1990, 58, 1429-1436. [PubMed]

56. Purschke, F.G.; Hiller, E.; Trick, I.; Rupp, S. Flexible survival strategies of Pseudomonas aeruginosa in biofilms result in increased fitness compared with Candida albicans. Mol. Cell. Proteomics 2012, 11, 1652-1669. [CrossRef] [PubMed]

57. Ovchinnikova, E.S.; Krom, B.P.; van der Mei, H.C.; Busscher, H.J. Force microscopic and thermodynamic analysis of the adhesion between Pseudomonas aeruginosa and Candida albicans. Soft Matter 2012, 8, 6454-6461. [CrossRef]

58. Silverman, R.J.; Nobbs, A.H.; Vickerman, M.M.; Barbour, M.E.; Jenkinson, H.F. Interaction of Candida albicans cell wall als3 protein with Streptococcus gordonii sspb adhesin promotes development of mixed-species communities. Infect. Immun. 2010, 78, 4644-4652. [CrossRef] [PubMed]

59. Hoyer, L.L.; Oh, S.H.; Jones, R.; Cota, E. A proposed mechanism for the interaction between the Candida albicans als3 adhesin and streptococcal cell wall proteins. Front. Microbiol. 2014, 5, 564. [CrossRef] [PubMed]

60. Gregoire, S.; Xiao, J.; Silva, B.B.; Gonzalez, I.; Agidi, P.S.; Klein, M.I.; Ambatipudi, K.S.; Rosalen, P.L.; Bauserman, R.; Waugh, R.E.; et al. Role of glucosyltransferase $b$ in interactions of Candida albicans with 
Streptococcus mutans and with an experimental pellicle on hydroxyapatite surfaces. Appl. Environ. Microbiol. 2011, 77, 6357-6367. [CrossRef] [PubMed]

61. Bruno, V.M.; Shetty, A.C.; Yano, J.; Fidel, P.L., Jr.; Noverr, M.C.; Peters, B.M. Transcriptomic analysis of vulvovaginal candidiasis identifies a role for the nlrp3 inflammasome. MBio 2015, 6. [CrossRef] [PubMed]

62. Fox, E.P.; Cowley, E.S.; Nobile, C.J.; Hartooni, N.; Newman, D.K.; Johnson, A.D. Anaerobic bacteria grow within Candida albicans biofilms and induce biofilm formation in suspension cultures. Curr. Biol. 2014, 24, 2411-2416. [CrossRef] [PubMed]

63. Villar, C.C.; Kashleva, H.; Nobile, C.J.; Mitchell, A.P.; Dongari-Bagtzoglou, A. Mucosal tissue invasion by Candida albicans is associated with e-cadherin degradation, mediated by transcription factor rim101p and protease sap5p. Infect. Immun. 2007, 75, 2126-2135. [CrossRef] [PubMed]

64. Cavalcanti, Y.W.; Morse, D.J.; da Silva, W.J.; Del-Bel-Cury, A.A.; Wei, X.; Wilson, M.; Milward, P.; Lewis, M.; Bradshaw, D.; Williams, D.W. Virulence and pathogenicity of Candida albicans is enhanced in biofilms containing oral bacteria. Biofouling 2015, 31, 27-38. [CrossRef] [PubMed]

65. Dwivedi, P.; Thompson, A.; Xie, Z.; Kashleva, H.; Ganguly, S.; Mitchell, A.P.; Dongari-Bagtzoglou, A. Role of bcr1-activated genes hwp1 and hyr1 in Candida albicans oral mucosal biofilms and neutrophil evasion. PLOS ONE 2011, 6, e16218. [CrossRef] [PubMed]

66. Chen, A.I.; Dolben, E.F.; Okegbe, C.; Harty, C.E.; Golub, Y.; Thao, S.; Ha, D.G.; Willger, S.D.; O’Toole, G.A.; Harwood, C.S.; et al. Candida albicans ethanol stimulates Pseudomonas aeruginosa wspr-controlled biofilm formation as part of a cyclic relationship involving phenazines. PLoS Pathog. 2014, 10, e1004480. [CrossRef] [PubMed]

67. Ader, F.; Jawhara, S.; Nseir, S.; Kipnis, E.; Faure, K.; Vuotto, F.; Chemani, C.; Sendid, B.; Poulain, D.; Guery, B. Short term Candida albicans colonization reduces Pseudomonas aeruginosa-related lung injury and bacterial burden in a murine model. Crit. Care 2011, 15, R150. [CrossRef] [PubMed]

68. Mear, J.B.; Gosset, P.; Kipnis, E.; Faure, E.; Dessein, R.; Jawhara, S.; Fradin, C.; Faure, K.; Poulain, D.; Sendid, B.; et al. Candida albicans airway exposure primes the lung innate immune response against Pseudomonas aeruginosa infection through innate lymphoid cell recruitment and interleukin-22-associated mucosal response. Infect. Immun. 2014, 82, 306-315. [CrossRef] [PubMed]

69. Lopez-Medina, E.; Fan, D.; Coughlin, L.A.; Ho, E.X.; Lamont, I.L.; Reimmann, C.; Hooper, L.V.; Koh, A.Y. Candida albicans inhibits Pseudomonas aeruginosa virulence through suppression of pyochelin and pyoverdine biosynthesis. PLoS Pathog. 2015, 11, e1005129. [CrossRef] [PubMed]

70. Koo, H.; Bowen, W.H. Candida albicans and Streptococcus mutans: A potential synergistic alliance to cause virulent tooth decay in children. Future Microbiol. 2014, 9, 1295-1297. [CrossRef] [PubMed]

71. Xu, H.; Jenkinson, H.F.; Dongari-Bagtzoglou, A. Innocent until proven guilty: Mechanisms and roles of streptococcus-candida interactions in oral health and disease. Mol. Oral Microbiol. 2014, 29, 99-116. [CrossRef] [PubMed]

72. Falsetta, M.L.; Klein, M.I.; Colonne, P.M.; Scott-Anne, K.; Gregoire, S.; Pai, C.H.; Gonzalez-Begne, M.; Watson, G.; Krysan, D.J.; Bowen, W.H.; et al. Symbiotic relationship between Streptococcus mutans and Candida albicans synergizes virulence of plaque biofilms in vivo. Infect. Immun. 2014, 82, 1968-1981. [CrossRef] [PubMed]

73. Lambooij, J.M.; Hoogenkamp, M.A.; Brandt, B.W.; Janus, M.M.; Krom, B.P. Fungal mitochondrial oxygen consumption induces the growth of strict anaerobic bacteria. Fungal Genet. Biol. 2017, 109, 1-6. [CrossRef] [PubMed]

74. Diaz, P.I.; Xie, Z.; Sobue, T.; Thompson, A.; Biyikoglu, B.; Ricker, A.; Ikonomou, L.; Dongari-Bagtzoglou, A. Synergistic interaction between Candida albicans and commensal oral streptococci in a novel in vitro mucosal model. Infect. Immun. 2012, 80, 620-632. [CrossRef] [PubMed]

75. Staib, P.; Kretschmar, M.; Nichterlein, T.; Hof, H.; Morschhauser, J. Differential activation of a Candida albicans virulence gene family during infection. Proc. Natl. Acad. Sci. USA 2000, 97, 6102-6107. [CrossRef] [PubMed]

76. Rosenbach, A.; Dignard, D.; Pierce, J.V.; Whiteway, M.; Kumamoto, C.A. Adaptations of Candida albicans for growth in the mammalian intestinal tract. Eukaryot. Cell 2010, 9, 1075-1086. [CrossRef] [PubMed]

77. Takakura, N.; Sato, Y.; Ishibashi, H.; Oshima, H.; Uchida, K.; Yamaguchi, H.; Abe, S. A novel murine model of oral candidiasis with local symptoms characteristic of oral thrush. Microbiol. Immunol. 2003, 47, 321-326. [CrossRef] [PubMed] 
78. Zakikhany, K.; Naglik, J.R.; Schmidt-Westhausen, A.; Holland, G.; Schaller, M.; Hube, B. In vivo transcript profiling of Candida albicans identifies a gene essential for interepithelial dissemination. Cell. Microbiol. 2007, 9, 2938-2954. [CrossRef] [PubMed]

79. Hebecker, B.; Vlaic, S.; Conrad, T.; Bauer, M.; Brunke, S.; Kapitan, M.; Linde, J.; Hube, B.; Jacobsen, I.D. Dual-species transcriptional profiling during systemic candidiasis reveals organ-specific host-pathogen interactions. Sci. Rep. 2016, 6, 36055. [CrossRef] [PubMed]

80. Andes, D.; Lepak, A.; Pitula, A.; Marchillo, K.; Clark, J. A simple approach for estimating gene expression in Candida albicans directly from a systemic infection site. J. Infect. Dis. 2005, 192, 893-900. [CrossRef] [PubMed]

81. Allert, S.; Brunke, S.; Hube, B. In vivo transcriptional profiling of human pathogenic fungi during infection: Reflecting the real life? PLoS Pathog. 2016, 12, e1005471. [CrossRef] [PubMed]

82. Boktour, M.R.; Kontoyiannis, D.P.; Hanna, H.A.; Hachem, R.Y.; Girgawy, E.; Bodey, G.P.; Raad, I.I. Multiple-species candidemia in patients with cancer. Cancer 2004, 101, 1860-1865. [CrossRef] [PubMed]

83. Puig-Asensio, M.; Ruiz-Camps, I.; Fernandez-Ruiz, M.; Aguado, J.M.; Munoz, P.; Valerio, M.; Delgado-Iribarren, A.; Merino, P.; Bereciartua, E.; Fortun, J.; et al. Epidemiology and outcome of candidaemia in patients with oncological and haematological malignancies: Results from a population-based surveillance in Spain. Clin. Microbiol. Infect. 2015, 21, 491. [CrossRef] [PubMed]

84. Holler, E.; Butzhammer, P.; Schmid, K.; Hundsrucker, C.; Koestler, J.; Peter, K.; Zhu, W.; Sporrer, D.; Hehlgans, T.; Kreutz, M.; et al. Metagenomic analysis of the stool microbiome in patients receiving allogeneic stem cell transplantation: Loss of diversity is associated with use of systemic antibiotics and more pronounced in gastrointestinal graft-versus-host disease. Biol. Blood Marrow Transplant. 2014, 20, 640-645. [CrossRef] [PubMed]

(C) 2018 by the authors. Licensee MDPI, Basel, Switzerland. This article is an open access article distributed under the terms and conditions of the Creative Commons Attribution (CC BY) license (http:/ / creativecommons.org/licenses/by/4.0/). 